This item was submitted to Loughborough's Research Repository by the author.

Items in Figshare are protected by copyright, with all rights reserved, unless otherwise indicated.

\title{
Off-road tire-terrain interaction: an analytical solution
}

PLEASE CITE THE PUBLISHED VERSION

http://dx.doi.org/10.4271/2016-01-8029

PUBLISHER

(C) SAE International

VERSION

VoR (Version of Record)

\section{PUBLISHER STATEMENT}

This work is made available according to the conditions of the Creative Commons Attribution-NonCommercialNoDerivatives 4.0 International (CC BY-NC-ND 4.0) licence. Full details of this licence are available at: https://creativecommons.org/licenses/by-nc-nd/4.0/

\section{LICENCE}

CC BY-NC-ND 4.0

\section{REPOSITORY RECORD}

Bekakos, Chrysostomos, George Papazafeiropoulos, Daniel O'Boy, Jan Prins, and Georgios Mavros. 2016. "Off-road Tire-terrain Interaction: An Analytical Solution". figshare. https://hdl.handle.net/2134/23044. 


\title{
Off-Road Tire-Terrain Interaction: An Analytical Solution
}

\author{
Chrysostomos-Alexandros Bekakos \\ Loughborough University \\ George Papazafeiropoulos \\ National Technical University of Athens
}

\author{
Dan J. O'Boy \\ Loughborough University \\ Jan Prins \\ Jaguar Land Rover \\ George Mavros \\ Smart Dynamics Ltd
}

\begin{abstract}
A novel semi-analytical solution has been developed for the calculation of the static and dynamic response of an off road tire interacting with a deformable terrain, which utilizes soil parameters independent of the size of the contact patch (size-independent). The models involved in the solution presented, can be categorized in rigid and/or pneumatic tires, with or without tread pattern. After a concise literature review of related methods, a detailed presentation of the semi-analytical solution is presented, along with assumptions and limitations. A flowchart is provided, showing the main steps of the numerical implementation, and various test cases have been examined, characterized in terms of vertical load, tire dimensions, soil properties, deformability of the tire, and tread pattern. It has been found that the proposed model can qualitatively capture the response of a rolling wheel on deformable terrain.
\end{abstract}

CITATION: Bekakos, C., Papazafeiropoulos, G., O'Boy, D., Prins, J. et al., "Off-Road Tire-Terrain Interaction: An Analytical Solution," SAE Int. J. Commer. Veh. 9(2):2016, doi:10.4271/2016-01-8029.

\section{INTRODUCTION}

Tire-road interaction is a highly complex dynamic phenomenon, which has been subject to extensive research and development within the automotive industry. The tire is the dominant link between a vehicle body and road surface dynamic interaction in terms of accelerating, braking and steering forces. On-road tires have attracted significant attention with regards to reducing rolling resistance and fuel consumption following several European and/or world guidelines. However, off-road tires-soil interaction occupies an equally important position within the tire industry not only for military purposes but also for the growth of agricultural-based countries' economies.

The ability of tracked and wheeled vehicles to transverse certain types of soft soils is a complex, multivariable phenomenon and because of this, several assumptions have to be made in order to create accurate and yet computationally efficient off-road tire models. Finite element models can produce highly accurate time-domain solutions, taking into account the exact properties of the tire and soil surface, however, they are typically unsuitable as inputs for interactive, dynamic vehicle simulations as they operate far from real time. Semi-analytical and/or numerical simplified models have been created in the past where the soil is being regarded as an elasticperfectly plastic material [1] and the tire is being considered as a rigid wheel model, representative of a highly inflated tire rolling on a very soft soil [2] ]. To the best of the authors' knowledge, regardless of the assumptions involved, in most of the models published in the literature the off-road tire-soil interaction is studied in terms of two main effects. The first tries to capture the relationship between the normal load and vertical displacement (sinkage) of the wheel into the soil; the second has to do with the shear stress-shear displacement developed on the tire-soil interface.

In a pioneering paper representative of the former effect [ $\underline{3}]$, based on the observation that the main resistance in a tire's movement is due to the effort to create a rut in order to transverse, Bernstein proposed eq. (1), which was later extended in a more generalized version, i.e. eq. (2), presented in [4]: 


$$
\begin{gathered}
\mathrm{p}=\mathrm{k} \cdot \mathrm{z}^{0.5} \\
\mathrm{p}=\mathrm{k} \cdot \mathrm{z}^{\mathrm{n}}
\end{gathered}
$$

Many researchers subsequently attempted to improve or even establish their own semi-analytical relationships based on experimental data and in situ measurements. The most known and widely used equations until now are eq. (3) developed in [5] and eq. (4) developed in [] . Both the aforementioned studies try to divide the global k soil factor of eq. (2) into a cohesive and frictional component, which would permit a more accurate and realistic soil response for a variety of materials. A significant contribution on the terramechanics literature was the inclusion of the wheel width $b$, on the overall pressure-sinkage response [ 6 ]. Some of the assumptions and limitations, common for both models are: (a) the use of a constant radial pressure distribution along the width of the tire and (b) the utilization of non-invariant soil parameters, which would necessitate case-dependent experimental soil measurements in order to extract the frictional and cohesive soil components.

$$
\begin{gathered}
\mathrm{p}=\left(\mathrm{k}_{\mathrm{c}} / \mathrm{b}+\mathrm{k}_{\varphi}\right) \cdot \mathrm{z}^{\mathrm{n}} \\
\mathrm{p}=\left(\mathrm{ck}_{\mathrm{c}}{ }^{\prime}+\gamma \mathrm{bk}_{\varphi}{ }^{\prime}\right)(\mathrm{z} / \mathrm{b})^{\mathrm{n}}
\end{gathered}
$$

Wong and Reece studied both driven and towed rigid wheels rolling on sand in a series of papers, and divided the contact patch of the wheel-soil interface into two failure zones [7]. The first zone is from the point where the wheel comes into contact with the soil up to the point where the maximum radial pressure occurs, $\theta_{\mathrm{M}}$, and the second zone is from the latter point up to the point where the wheel loses its contact with the soil, $\theta_{\mathrm{r}}$, illustrated in Fig.1. Following this work, and based on eq. (4) they proposed eq. (5).

In []ㅡ, which was based on []], the indentation of a rigid plate on various soft soils was studied and a Load Sinkage Analytical (LSA) model was developed, described by eq. (6), which is based on four invariant soil parameters (cohesion, friction angle, density and modulus of elasticity of the soil) which can be given or measured for any terrain using classical soil mechanics or routine test methods (through hand held instruments). In this study a novel approach is developed, which is based on an extension of the work presented in []], with the following modifications: (a) it implements the two failure zones defined in [7], and (b) it applies eq. (6) to infinitesimal segments resulting from the discretization of the footprint of a rigid or deformable wheel.

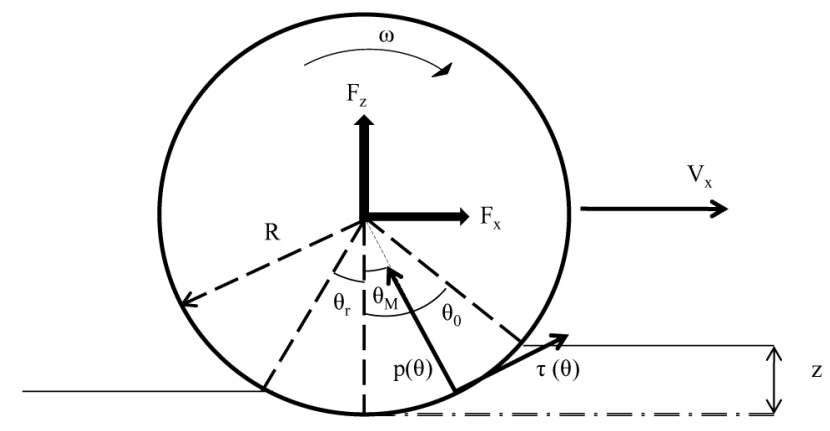

Figure 1. Schematic representation of a rigid wheel rolling on soft soil with two failure zones.

$$
\mathrm{p}(\theta)=\left\{\begin{array}{c}
\left(\mathrm{ck}_{\mathrm{c}}^{\prime}+\gamma \mathrm{bk}_{\varphi}^{\prime}\right)\left(\frac{\mathrm{r}}{\mathrm{b}}\right)^{\mathrm{n}}\left(\cos \theta-\cos \theta_{0}\right)^{\mathrm{n}}, \theta_{\mathrm{M}} \leq \theta<\theta_{0} \\
\left(\mathrm{ck}_{\mathrm{c}}^{\prime}+\gamma \mathrm{bk_{ \varphi } ^ { \prime }}\right)\left(\frac{\mathrm{r}}{\mathrm{b}}\right)^{\mathrm{n}} \cdot \\
{\left[\cos \left(\theta_{0}-\left(\frac{\theta-\theta_{\mathrm{r}}}{\theta_{\mathrm{M}}-\theta_{\mathrm{r}}}\right)\left(\theta_{0}-\theta_{\mathrm{M}}\right)\right)-\cos \theta_{0}\right]^{\mathrm{n}}, \theta_{\mathrm{r}} \leq \theta<\theta_{\mathrm{M}}} \\
\mathrm{p}=\frac{1}{\frac{\mathrm{D}_{1}}{\mathrm{~B}_{\mathrm{i}}}+\frac{\mathrm{D}_{2}}{\mathrm{E} \cdot \mathrm{z}} \cdot \omega_{1} \cdot \mathrm{B} \cdot \xi}
\end{array}\right.
$$

With regards to the second main effect which is related to shear stress-shear displacement relationship, three main approaches have been developed $[\underline{10}, \underline{11}]$. In the first approach presented in $[\underline{10}]$, eq. (7) has been presented, which is representative of soils not exhibiting a hump in their shear stress - shear displacement diagrams, such as loose sand, saturated clay, dry fresh snow and most of the disturbed soils. In these types of soils, with increasing the shear displacement, the shear stress increases monotonically up to a certain value, where it stabilizes after a certain value of the shear displacement.

$$
\tau=(\mathrm{c}+\mathrm{p} \cdot \tan \varphi)\left[1-\mathrm{e}^{-\mathrm{j} / \mathrm{K}}\right]
$$

In the second and third approaches presented in [11], relations are presented which are representative of materials exhibiting a "hump" near the maximum shear stress, and after passing this limit, the shear stress may decrease continuously (second approach), or stabilize to a certain value (third approach). For the second approach, presented in [11], eq. (8) has been proposed, representative of soils which exhibit a "hump" of maximum shear stress and then by further increasing the shear displacement the shear stress continuously decreases.

$$
\tau=(c+p \cdot \tan \varphi)\left(j / K_{w}\right) e^{\left(1-j / K_{w}\right)}
$$

With regards to the third category of shear stress response, herein the shear stress exhibits a "hump" and then by further increasing the shear displacement it decreases to a constant value. The equation describing this response was established in its final form as in eq. (9). 
However, as stated in [18], $K_{r}$ and $K_{w}$ used in eqs. (8) and (9) are non-invariant soil plate parameters and can be determined only experimentally. In this study eq. (7) is used to describe the shear stress developed at the tyre-soil interface.

$$
\tau=(\mathrm{c}+\mathrm{p} \cdot \tan \varphi) \mathrm{K}_{\mathrm{r}} \cdot\left\{1+\left[\frac{1}{\mathrm{~K}_{\mathrm{r}}\left(1-\frac{1}{\mathrm{e}}\right)}-1\right] \mathrm{e}^{\left(\frac{\mathrm{j}}{\mathrm{K}_{\mathrm{w}}}\right)}\right\}\left(1-\mathrm{e}^{\left(1-\frac{\mathrm{j}}{\mathrm{K}_{\mathrm{w}}}\right)}\right)
$$

In [7] eq. (10) is proposed for a driven wheel, which is the most widely adopted relationship for the description of the shear displacement as a function of slip (used in the present study):

$$
\mathrm{j}=\mathrm{R}\left[\left(\theta_{0}-\theta\right)-(1-\mathrm{i})\left(\sin \theta_{0}-\sin \theta\right)\right]
$$

Based on the semi-empirical equations presented so far, which are restricted to the most fundamental, various researchers have developed semi-analytical models applied either on rigid or flexible tires. It should be highlighted that use of the aforementioned equations, including their inherent limitations such as, the inability to predict the additional sinkage caused by the slipping conditions of the wheel, may lead to large errors and unrealistic response of the rolling wheel. Following this limitation, in [12] a new model is proposed where the initially constant exponent of deformation is replaced by a function of slip, as in eq. (11). The accuracy of the latter equation is assessed though a series of experiments and close agreement with experimental results is observed in the dynamic sinkage predictions.

$$
\mathrm{N}=\mathrm{n}_{0}+\mathrm{n}_{\mathrm{l}} \mathrm{i}
$$

Among the solutions targeted for flexible tires, a first direction was given by Bekker, who expressed the basic idea of the replacement of a deformable wheel by a larger substitute circle. Following that, in [13], the aforementioned idea was implemented and satisfactory results close to experimental data were obtained. Moreover, equations were given for a flexible tire with a more solid theoretical approach, where the tire properties were related to its vertical deformation [14]. Furthermore, in [15], the equations proposed in [14] were used along with additional modifications to propose an enhanced tire-soil interaction model, capable of accurately predicting the traction, the slip sinkage and the multipass effect.

Regarding treaded wheels, in [16] two different pressure distributions were considered, the first being applied at the lug tips, and the other being applied on the carcass between the lugs. Following this the overall pressure distribution was given as the sum of the two aforementioned pressures, weighted with the tread and void ratios respectively. In [13] , a new approach (which was initially proposed in $[17]$ ), to consider the negative (void) and positive (tread) portions of the tire is presented where the soil is assumed to be interlocked between the tread blocks and acting only in a shear mode. Based on the soil cutting theory of soil mechanics, the forces normal to the sides of the treads were estimated and their contribution on the overall tractive performance was considered in [18] .

\section{TIRE-SOIL INTERACTION MODELING}

In this section, the mechanics of a rigid or deformable wheel (with or without tread pattern) in contact with loose soil is addressed. A novel semi-analytical solution is described, as well as its assumptions and limitations are outlined. This solution can capture the static and dynamic response of four different models (rigid-treadless, deformable-treadless, rigid-treaded and deformable-treaded). Two types of sinkage may be identified for each model: static sinkage $\left(\mathrm{z}_{\text {static }}\right)$ and dynamic sinkage $\left(\mathrm{z}_{\text {dynamic }}\right)$, where $\mathrm{z}_{\text {dynamic }}$ is a function of slip and for increasing slip, the so-called digging effect is more pronounced, leading thus to increased $\mathrm{z}_{\text {total }}$. This section is organized in two parts: firstly, the assumptions of the new solution are mentioned; afterwards, a flowchart of the calculations is presented and explained.

\section{Assumptions}

The tire is assumed to interact with homogeneous soil, described by invariant parameters. It is considered that no stress concentrations are present, and the vertical load does not exceed the bearing capacity of the soil, as described by the Terzaghi theory. The tire is assumed to move only in the longitudinal direction with no side forces affecting the overall traction. The pressures acting on the tire are assumed to be in the radial direction and constant along the width of the tire.

Regarding the treaded wheels, interlocking action is assumed for the soil inside the region between the successive tread blocks; this means that the soil acts only in a shear mode. For the external surface of the tread blocks, the minimum force given by either the friction force (stemming from the vertical load and given by the Coulomb friction law) or the maximum shear force (which develops due to the stresses in the soil and is given by the Mohr-Coulomb law) is selected, since the shear strength of the tire-soil system is determined by the weaker of the above two types of shear strengths.

The contact patch of any deformable tire is considered to be described by the geometry of a larger substitute circle, as initially proposed by Bekker. As far as the tread pattern is concerned, the void inbetween the tread blocks is assumed to be fully filled with soil, and the contribution of the forces acting normal to the surfaces of the tread pattern which are perpendicular to the carcass to the tire response is neglected.

\section{Static Sinkage}

The configuration of the wheel model is shown in Fig. 2. The angle $\theta_{s}$ is the static entry angle and becomes zero at the point where the maximum pressure occurs. The pressure distribution is symmetric; only the part involving the positive angle $\theta$ is considered in the integration and then the result is doubled. The tire footprint is discretized into a large number of segments (typically $\geq 1000$ ), at each of which the soil pressures are calculated according to eq. (12): 


$$
\mathrm{p}=\frac{1}{\frac{\mathrm{D}_{1}}{\mathrm{~B}_{\mathrm{i}}}+\frac{\mathrm{D}_{2} \cdot \omega_{1} \cdot \xi \cdot[\sin (\theta+\mathrm{d} \theta)-\sin (\theta)]}{\mathrm{E} \cdot\left[\cos (\theta)-\cos \left(\theta_{\mathrm{s}}\right)\right]}}
$$

where $\mathrm{D}_{1}, \mathrm{D}_{2}$ are given by the relations:

$$
\begin{aligned}
& \mathrm{D}_{1}=\frac{2}{\pi} \cdot \operatorname{atan}\left[\frac{\pi \cdot\left(\mathrm{H}_{0}-\mathrm{z}\right)}{2 \cdot \mathrm{dL}}\right] \\
& \mathrm{D}_{2}=\operatorname{atan}\left(\frac{\mathrm{H}_{0}-\mathrm{z}}{\mathrm{A}_{0} \cdot \mathrm{dL}}\right)
\end{aligned}
$$

and $\mathrm{z}, \mathrm{dL}$ are given by the relations:

$$
\begin{aligned}
& \mathrm{z}=\mathrm{R} \cdot\left[\cos (\theta)-\cos \left(\theta_{\mathrm{s}}\right)\right] \\
& \mathrm{dL}=\mathrm{R} \cdot[\sin (\theta+\mathrm{d} \theta)-\sin (\theta)]
\end{aligned}
$$

respectively. It should be noted that in eq. (6), B is the smaller dimension of the segment, in this case being its infinitesimal length, given that the width is unique for all segments. The soil pressures are considered to be constant along each segment, and dependent on the local sinkage of each segment. The integration is performed by the summation of the forces (pressures multiplied by the infinitesimal area of each segment), and gives the total reaction force of the soil. If the soil reaction force, calculated as:

$$
F_{z}=2 \cdot R \cdot b \cdot \int_{0}^{\theta_{s}} p \cdot \cos (\theta) \cdot d \theta
$$

is different from the applied vertical load, the value of the sinkage is updated according to the bisection method, in a way that leads to decrease of the difference, until the last gets lower than a specified tolerance, a point at which the assumed value of sinkage is accepted as a solution. The angle $\theta_{\mathrm{s}}$ is defined as:

$$
\theta_{\mathrm{s}}=\operatorname{acos}\left(1-\frac{\mathrm{z}_{\text {static }}}{\mathrm{R}}\right)
$$

The number of infinitesimal segments considered for the integration was determined in this study using criteria related to the convergence of the desired results. Apart from this, given the relatively large approximation inherent in the numerical values of the produced results in practice (for example due to the inaccuracies in the determination of the soil parameters), usually there is no need for convergence within very small tolerances and consequently for large degree of discretization and therefore increased computational efforts.

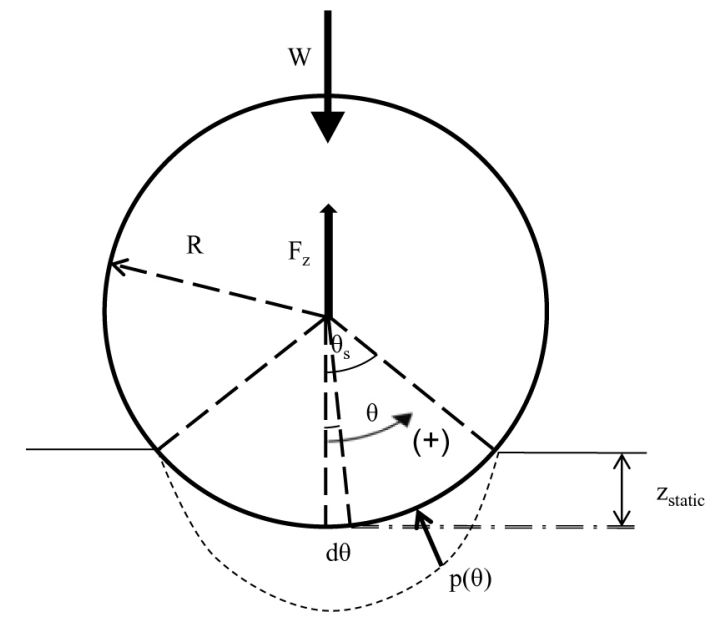

Figure 2. Static indentation of a rigid wheel.

\section{Dynamic Sinkage}

After the calculation of the static sinkage, the dynamic sinkage is found from the relationship given in [19]:

$$
\mathrm{z}_{\text {dynamic }}=\frac{1+\mathrm{i}}{1-0.5 \cdot \mathrm{i}} \cdot \mathrm{z}_{\text {static }}
$$

where $i$ is the slip ratio. Equation (17) has been verified by many tests, [19], on various vehicles (tracked, wheeled) and for numerous soil conditions. The effect of the slip ratio on the dynamic sinkage of a wheel is illustrated in Fig. 3. It is apparent that, as the slip ratio increases, the dynamic sinkage also increases, in accordance with eq. (17).

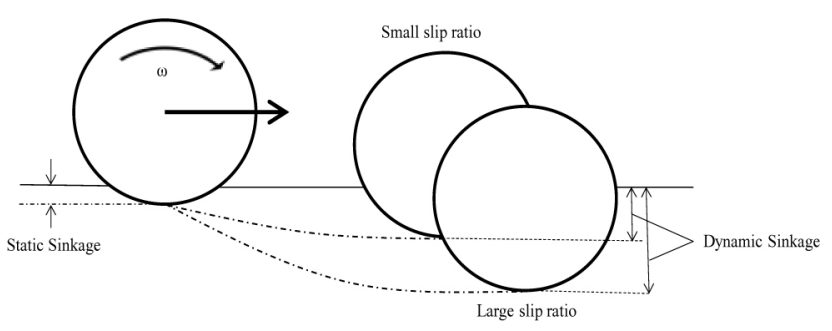

Figure 3. Effect of slip ratio on the dynamic sinkage.

In the reference configuration of a rigid wheel experiencing dynamic response, shown in Fig. 4, it is apparent that there is a rebound effect of the deformed soil after the wheel passes along its surface, i.e. the point $\mathrm{C}$ behind the point with the maximum sinkage (point $\mathrm{A}$ ), is at a higher level than the last. It is assumed that the footprint is divided into two regions, defined by the angle $\theta_{\mathrm{M}}$, in each of which different soil pressure relationships hold. These are given in eq. (18):

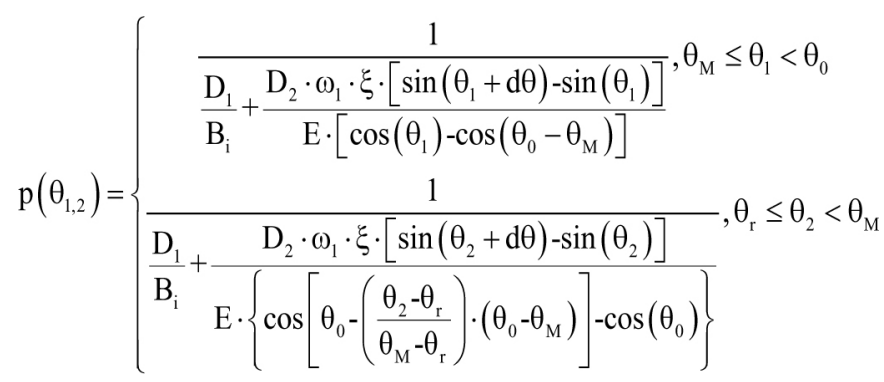


The various angles appearing in Fig. 4 and eq. (18) are given by the relations:

$$
\begin{aligned}
& \theta_{0}=\operatorname{acos}\left(1-\frac{\mathrm{z}_{\mathrm{dynamic}}}{\mathrm{R}}\right) \\
& \theta_{\mathrm{M}}=\left(\alpha_{0}+\alpha_{1} \cdot \mathrm{i}\right) \cdot \theta_{0} \\
& \theta_{\mathrm{r}}=\operatorname{acos}\left(1-\frac{\mathrm{k}_{\mathrm{r}} \mathrm{z}_{\text {dynamic }}}{\mathrm{R}}\right)
\end{aligned}
$$

where $\mathrm{k}_{\mathrm{r}}, \mathrm{a}_{0}$ and $\mathrm{a}_{1}$ are estimated as $0.2,0.4$ and 0.2 respectively. The latter parameters were estimated assuming that the realistic physical response of a rolling wheel on a cohesive soil will be maintained. Initially parameter $\mathrm{k}_{\mathrm{r}}$ was set to $\mathrm{k}_{\mathrm{r}}<1$, representative for soil where compaction occurs. Furthermore, $\mathrm{k}_{\mathrm{r}}$ is directly related with the exit angle and is primarily responsible for the re-bouncing effect of the soil, namely the decrease of the total sinkage of the soil after the wheel passage. Values for $\mathrm{a}_{0}$ and $\mathrm{a}_{1}$ were estimated based on experimental results found in the literature (i.e [7],[11],[20]). Future validation of the proposed model will involve the experimental determination of the above-stated parameters for given soil conditions.

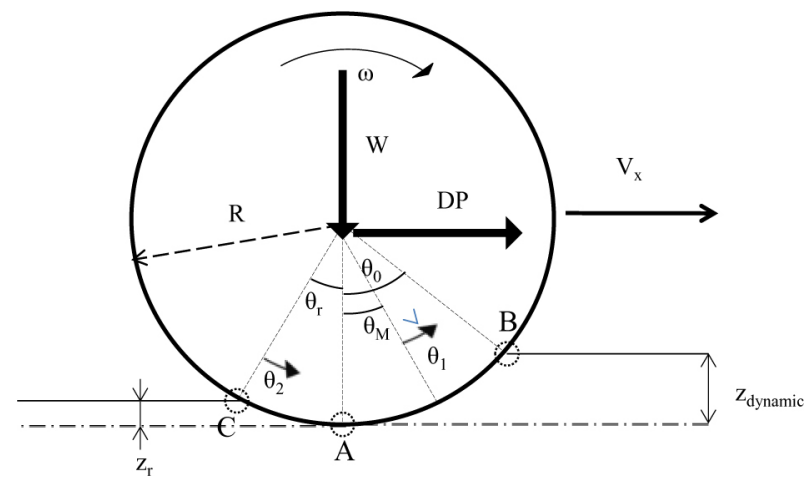

Figure 4. Reference configuration for a driven wheel rolling on a soft soil.

The shear stresses developed on the tire soil interface, are given by suitable combination of eqs. (7) and (10), for the two ranges of integration. Finally, the so-called drawbar pull (DP) is calculated as follows:

$$
\begin{aligned}
\text { DP } & =\text { Soil thrust }- \text { Compaction Resis tance } \\
& =\mathrm{R} \cdot \mathrm{b} \cdot\left[\int_{\theta_{\mathrm{r}}}^{\theta_{0}} \tau \cdot \cos (\theta) \mathrm{d} \theta-\int_{\theta_{\mathrm{r}}}^{\theta_{0}} \mathrm{p} \cdot \sin (\theta) \mathrm{d} \theta\right]
\end{aligned}
$$

\section{Deformable Tire}

The basic principle used in the present study to model a deformable tire is presented in $[\underline{5}, \underline{13}]$, where the contact patch of the pneumatic tire is assumed to be represented by the contact patch of a larger substitute circle with radius given by:

$$
\mathrm{R}^{*}=\mathrm{R} \cdot(\sqrt{1+\mathrm{DF} / \mathrm{z}}+\sqrt{\mathrm{DF} / \mathrm{z}})^{2}
$$

where

$$
\mathrm{DF}=\frac{\mathrm{W}}{\mathrm{C}_{\mathrm{z}}}
$$

The substitute circle is considered as a rigid wheel with larger radius given by eq. (21), and is analyzed with the methodology outlined in the previous section to obtain its static and dynamic response. From this response, the static sinkage of the initial deformable wheel is calculated as follows. Firstly, the initial undeformed geometry of the deformable wheel is considered as a reference configuration with respect to which all values of sinkage are calculated. This reference configuration is considered undeformable and is mapped to the geometry of the substitute circle at each equilibrium iteration. At the substitute circle, the difference between the total reaction force and the vertical load is calculated, and, if larger than a specified tolerance, the iterations proceed, by modifying appropriately the sinkage of the reference configuration (undeformed pneumatic tire). Therefore, as static equilibrium is achieved, the resulting sinkage (denoted as $\mathrm{z}_{\text {maxstatic,ref }}$ ) will refer to the reference configuration, from which the sinkage of the deformable tire has to be found (denoted as $\mathrm{z}_{\text {maxstatic,def }}$ ). The relationship between the last two is:

$$
\mathrm{z}_{\text {max static,def }}=\mathrm{z}_{\text {max static,ref }}-\left\{\mathrm{R}\left[1-\cos \left(\theta_{\mathrm{s}}\right)\right]-\mathrm{R}^{*}\left[1-\cos \left(\theta_{\mathrm{s}}^{*}\right)\right]\right\}
$$

It has to be noted that if the initial tire is highly inflated, then $\mathrm{R}^{*}=\mathrm{R}$ and $\theta_{\mathrm{s}} *=\theta_{\mathrm{s}}$, meaning that $\mathrm{z}_{\text {maxstatic,def }}=\mathrm{z}_{\text {maxstatic,ref }}$, according to eq. (23). The above procedure is illustrated in Fig. 5 .

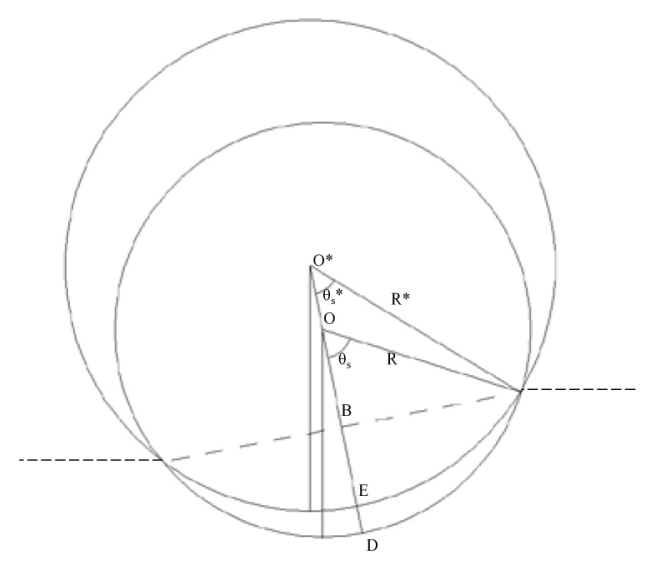

Figure 5. Reference configuration of a pneumatic tire, and the equivalent substitute circle.

\section{Tread Pattern}

The effect of tread pattern is taken into account in the formulation of the models considered in this study. A similar approach to the one followed in [13] has been adopted. The basic idea is that the response of a treaded tire is considered as the sum of the responses of two treadless tires with radii equal to the outer and the inner radius of the initial treaded tire, weighted according to the void ratio (the fraction of the voids along the tire perimeter to its total perimeter). Regarding the dynamic response, the dynamic sinkage is calculated by eq. (17), 
for the tread blocks, whereas for the voids the sinkage is assumed to be equal to the dynamic sinkage of the treads minus the height of the tread blocks.

\section{Semi-Analytical Procedure}

In the flowchart shown in Fig. 6, an outline of the semi-analytical procedure followed in this study is provided.

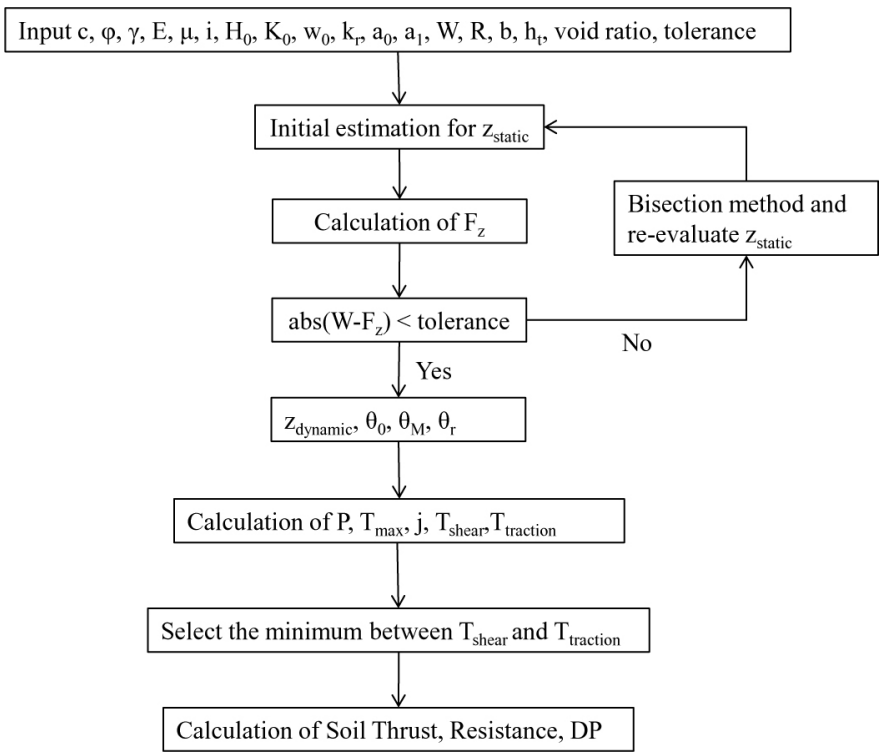

Figure 6. Flowchart of the semi-analytical procedure followed in this study.

\section{RIGID TREADLESS WHEEL RESPONSE}

The most fundamental model among those examined in this study is the tire without any tread pattern, which behaves as a rigid wheel. This may occur due to many reasons, e.g. in case a deformable tire is highly inflated, or a tire with intermediate inflation pressure rolling on a very soft soil. In particular, the assumption of rigid wheel is very common in the field of terramechanics, especially when the soil response is emphasized. In Fig. 7 the response of a rigid wheel rolling on wet clay is shown in terms of its drawbar pull versus its slip ratio. It is noted that as the vertical load increases, the curve becomes steeper and has higher maximum drawbar pull and lower minimum drawbar pull. In addition, it is observed that for positive values of slip ratio, the variation of the drawbar pull for various vertical loads is less pronounced than that for negative values of slip, since the resistance force is always opposite to the direction of travel. Drawbar pull becomes positive at approximately $5 \%$ slip ratio, and stabilizes at its maximum value after $20 \%$ slip ratio.

In Fig. 8 the drawbar pull is plotted for two different wheels with equal diameters $(0.8728 \mathrm{~m})$ and widths equal to $0.315 \mathrm{~m}$ and $0.215 \mathrm{~m}$. It is observed that the wheel with larger width is developing larger drawbar pull compared to the narrower wheel, which can be explained by taking into account that the wheel with larger width experiences lower sinkage due to the larger footprint area. This leads in turn to lower compaction resistance. In addition the wider wheel due to its larger contact area develops higher shear force.

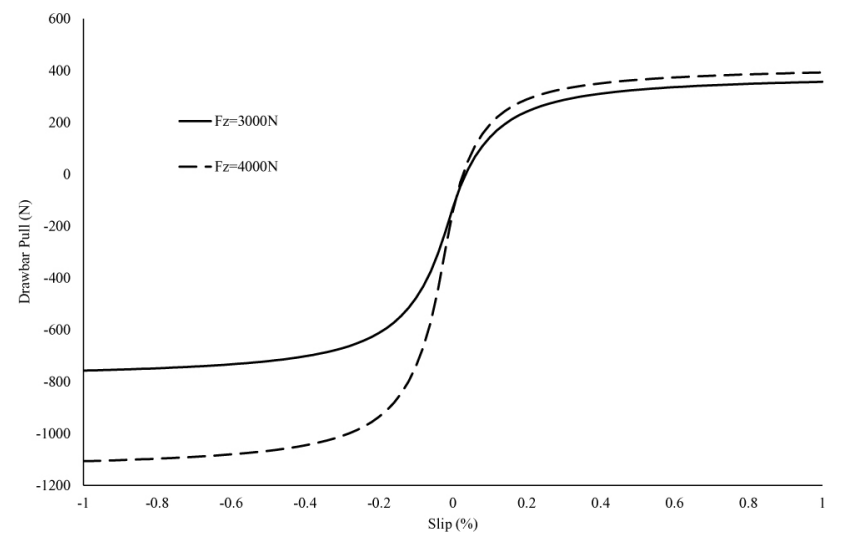

Figure 7. Drawbar pull developed for a rigid wheel rolling on wet clay with various vertical loads, versus its slip ratio.

In Fig. 9 the total sinkage (which is equal to the dynamic sinkage) of a rigid wheel with width $0.215 \mathrm{~m}$, diameter $0.8728 \mathrm{~m}$, and vertical load equal to $4 \mathrm{kN}$ is plotted against the slip ratio, for two different types of underlying soil, namely moist loam and wet clay. It is observed that the dynamic sinkage increases with increasing slip ratio, a result which is well-documented in the literature $[\underline{15}, \underline{19}]$, and can be explained by considering the digging action of any driven wheel with increasing slip. Generally, the sinkage seems to be larger for the wet clay than the moist loam, and does not increase linearly for increasing slip in both soil cases.

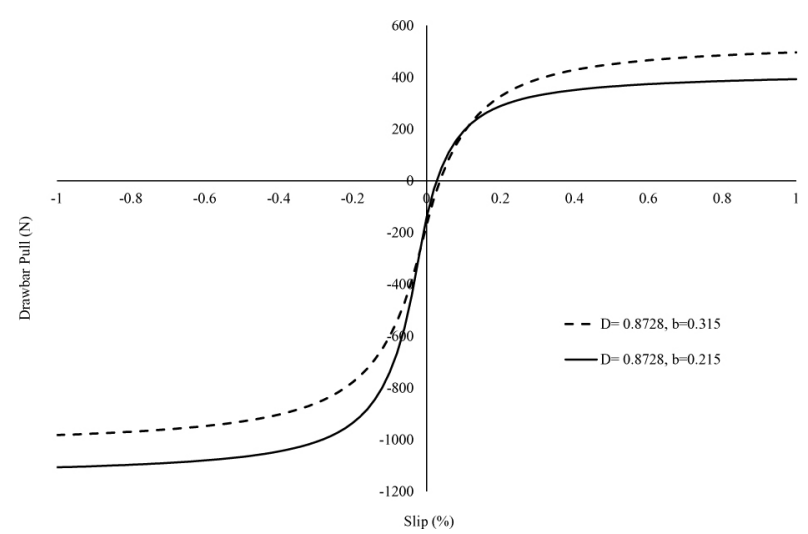

Figure 8. Drawbar pull developed for two rigid wheels of different width, rolling on wet clay with vertical load equal to $\mathrm{F}_{\mathrm{z}}=4 \mathrm{kN}$, versus slip ratio.

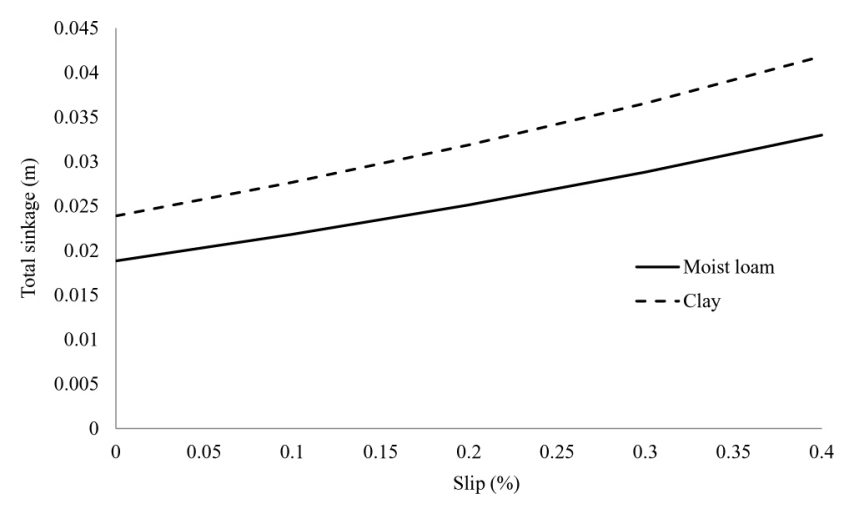

Figure 9. Total sinkage versus slip ratio for a rigid wheel with dimensions $\mathrm{b}=0.215 \mathrm{~m}, \mathrm{D}=0.8728 \mathrm{~m}$ and vertical load $\mathrm{F}_{\mathrm{z}}=4 \mathrm{kN}$, for two different types of soil. 


\section{RIGID TREADED WHEEL RESPONSE}

The tread pattern has been taken into account by weighting respective results extracted for two wheels, one with the outer diameter of the tread pattern and one with the inner diameter of the void. It should be noted that the vertical load should be sufficiently high in order to ensure that the voids are fully occupied by soil. In Fig. 10, a treadless and a treaded wheel are compared. The two wheels have the same dimensions and the same vertical load. The treaded wheel has tread height 0.03 and void ratio 0.3 . Comparison of the two curves shows that the treaded wheel shows larger drawbar pull for positive slip ratios and smaller drawbar pull for negative slip ratios, whereas its curve is steeper, compared to the treadless wheel. It should be noted that by increasing the void ratio, the behavior of the soil interlocked within the voids is occupying a larger portion on the overall tractive response. However, the last should not exceed the value of 0.5 , since this implies that the wheel under consideration would have a smaller radius.

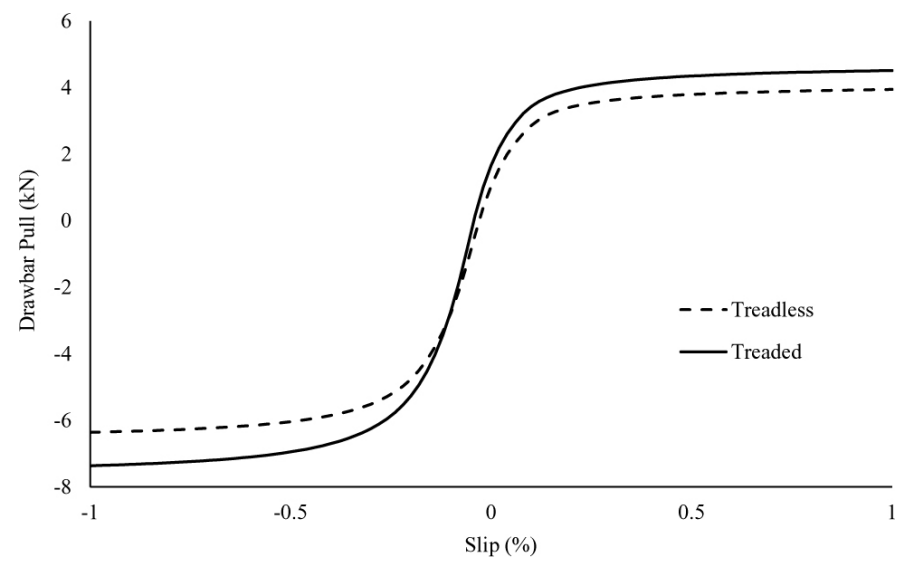

Figure 10. Drawbar pull developed for a treadless and a treaded rigid wheel, rolling on moist loam with vertical load equal to $\mathrm{F}_{\mathrm{z}}=10 \mathrm{kN}$, versus slip ratio.

\section{DEFORMABLE WHEEL RESPONSE}

In this section, results about treadless and treaded deformable tires are presented. The main parameter controlling the deformability of the tire is $\mathrm{C}_{\mathrm{z}}$, which is a function of its properties. Herein, $\mathrm{C}_{\mathrm{z}}$ will be used as a measure of the inflation pressure; high values of $\mathrm{C}_{\mathrm{z}}$ will imply a highly inflated tire behaving as a rigid wheel and moderate values $\left(10^{5}-5.10^{5}\right)$ will imply inflation pressures ranging from $80 \mathrm{kPa}$ to $250 \mathrm{kPa}$. In Fig. 11 a highly inflated pneumatic tire with a moderately inflated pneumatic tire are compared. It is obvious from Fig. 11 that the moderately inflated tire exhibits larger drawbar pull in general. This is caused mainly by the fact that larger footprint area is associated with moderately inflated tires, resulting in smaller sinkage of the tire into the soil, and thus in smaller values of compaction resistance. Following this, it should be noted that, contrary to the on-road tires, where high inflation pressure is recommended (reducing rolling resistance) the off-road tires behave better for moderate values of inflation pressure.

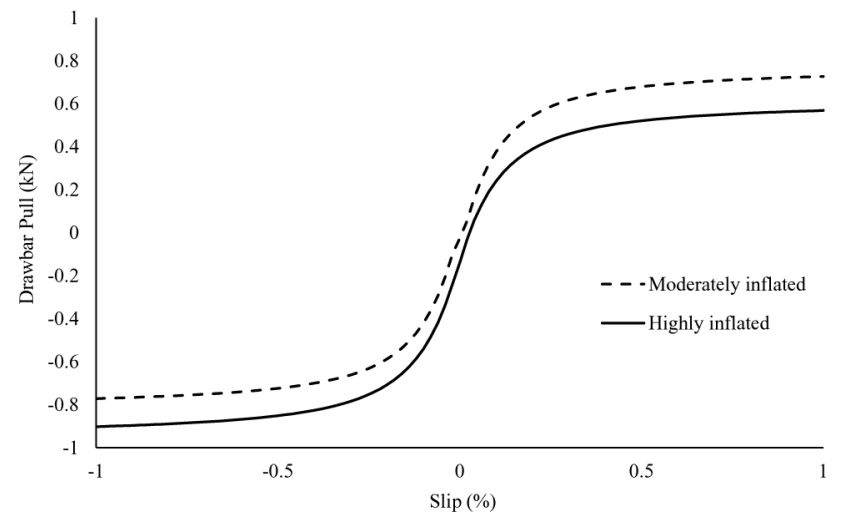

Figure 11. Drawbar pull developed for a pneumatic highly inflated tire and a pneumatic moderately inflated tire, rolling on moist loam with vertical load equal to $\mathrm{F}_{\mathrm{z}}=4 \mathrm{kN}$, versus slip ratio.

\section{CONCLUSIONS}

In this study a novel semi-analytical solution has been developed to calculate the static and dynamic response of tires. The tires considered can be either deformable or rigid, and either treaded or treadless. The qualitative response presented in the results is a clear indication that the proposed model can efficiently capture the basic characteristics of a rolling tire. Although the qualitative response implies the applicability of the mathematical formulation of the proposed model, future experimental validation is necessary prior to the complete assessment of the proposed model. Based on the numerical predictions produced from the proposed semi-analytical model, it has been observed that for higher vertical loads, the drawbar pull - slip curve becomes steeper and has higher maximum drawbar pull and lower minimum drawbar pull. However, the difference at the maximum drawbar pull is not so intense, since the maximum drawbar pull is constrained by the soil strength. Furthermore, the tires with larger width are experiencing lower vertical displacement, resulting in smaller compaction resistance and higher drawbar pull. Moreover, the soil interlocked in the void ratio has the effect of increasing the drawbar pull in the case of treaded tires. In addition, the inflation pressure affects the overall rolling response of a pneumatic tire, with the drawbar pull decreasing for increasing inflation pressure, a phenomenon caused by the higher values of vertical displacement. Finally once the model accuracy has been established, the next step will be the incorporation of the model into a Multi Body Simulation (MBS) software, where further investigation on the dynamic behavior of an off-road vehicle rolling on various types of cohesive and frictional soils will be performed.

\section{REFERENCES}

1. Bekakos, C.A., Papazafeiropoulos, G., O’Boy, D.J., Prins, J. "Dynamic Response of Rigid Wheels on Deformable Terrains" Proc. 13th ISTVS European Conf., Rome, pp. 588-600, 2015.

2. Hambleton, J.P., and Drescher, A., " Modeling Wheel-Induced Rutting in Soils: Rolling", Journal of Terramechanics, 46:35-47, 2009.

3. Bernstein, R., "Probleme zur Experimentellen Motorpflug-mechanik", Motorwagen, 16, 1913.

4. Goriatchkin, B.P., "Theory and Manufacturing of Agricultural Machines", Moscow, USSR Government, 1936.

5. Bekker, M.G., "Theory of Land Locomotion", The University of Michigan Press, Ann Arbor, 1956. 
6. Reece, A., "Principles of Soil-Vehicle Mechanics", Proc. Inst. Mech. Engineers, Automobile Division, 1965.

7. Wong, J.Y, and Reece, A., "Prediction of Rigid Wheel Performance Based on Analysis of Soil-Wheel Stresses, Part I: Performance of Driven Rigid Wheels", Journal of Terramechanics, 4:81-98, 1967.

8. Lyasko, M., "LSA Model for Sinkage Predictions", Journal of Terramechanics, 47(1):1-19, 2010

9. Ageikin, J., "Off-the-road mobility of automobiles", New Delhi: Amerind Pub.Co, 1981.

10. Janosi, Z., Hanamoto, B., "The Analytical Determination of Drawbar Pull as a Function of Slip for Tracked Vehicles in Deformable Soils", Proc. 1st Int. Conf. on the Mechanics of Soil-Vehicle Systems, Torino, Italy, 1961

11. Wong, J.Y., “Terramechanics and Off-Road Vehicles”, Ottawa, Canada, Elsevier, 1989.

12. Ding, L., Gao, H., Deng, Z., Tao, J. (2010). "Wheel slip-sinkage and its prediction model of lunar rover", Journal of Central South University of Technology, 17(1), 129-135.

13. Harnisch, C., Lach, B., Jakobs, R., Troulis, M., et al., "A New Tyre-Soil Interaction Model for Vehicle Simulation on Deformable Ground", Vehicle System Dynamics: International Journal of Vehicle Mechanics and Mobility, 43:sup1, 384-394, 2005.

14. Chan, B.J., and Sandu, C., "Development of an off-road capable tire model for vehicle dynamics simulation", $\mathrm{PhD}$ thesis, Virginia Polytechnic Institute and State University, Blacksburg, VA, 2008

15. Senatore, C., and Sandu, C., "Off-road Tyre Modeling and the Multi-pass Effect for Vehicle Dynamics Simulation", Journal of Terramechanics, 48:265-276, 2011.

16. El-Gawwad, K.A.A., Crolla, D.A., Soliman, A.M.A., and El-Sayed, F.M., "Off road tyre modelling I: the multi-spoke tyre model modified to include the effect of straight lugs", Journal of Terramechanics, 36:3-24, 1999.

17. Steiner, M., "Analyse, Synthese und Berechnungsmethoden der Triebkraft-Schlupf-Kurve von Luftreifen auf nachgiebigem Boden", Dissertation, Technische Universität München, 1979.

18. Trease, B., Arvidson, R., Lindemann, R., Bennett, K., et al., "Dynamic modeling and soil mechanics for path planning of the mars exploration rovers", Proc. ASME 2011 Int. Des. Engrg Tech. Conf. and Computers and Information in Engrg Conf., 755-765, 2011.

19. Lyasko, M., "Slip sinkage effect in soil-vehicle mechanics", Journal of Terramechanics, 47(1):21-31, 2010.

20. Ishigami, G. (2008). Terramechanics-based Analysis and Control for Lunar/Planetary Exploration Robots. PhD thesis, Tohoku University.

\section{CONTACT INFORMATION}

Chrysostomos - Alexandros Bekakos

Department of Aeronautical and Automotive Engineering

Loughborough University, Loughborough, Leicestershire, LE11 3TU, United Kingdom

c.bekakos@,1boro.ac.uk

\section{ACKNOWLEDGMENTS}

This work was supported by Jaguar Land Rover and the UK-EPSRC grant EP/K014102/1 as part of the jointly funded Programme for Simulation Innovation.

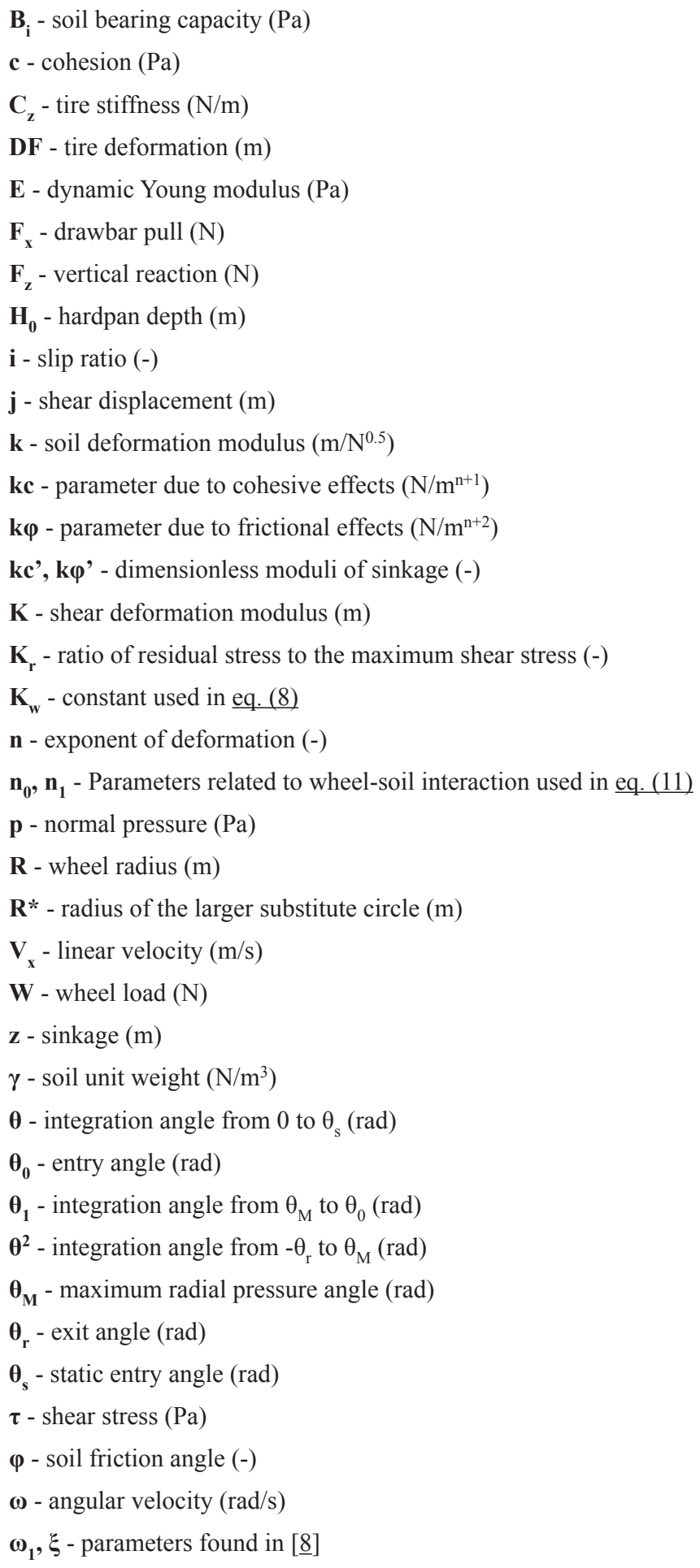

\section{NOMENCLATURE}

$\mathbf{A}_{0}$ - Ageikin's coefficient (-)

b - wheel width (m)

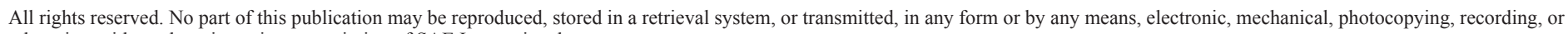
otherwise, without the prior written permission of SAE International. 